\title{
Landscape and climatic characteristics associated with human alveolar echinococcosis in France, 1982 to 2007
}

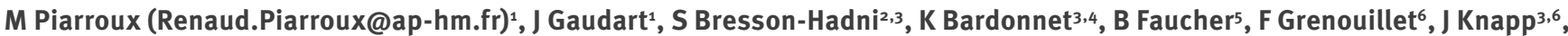 \\ J Dumortier ${ }^{7}$, J Watelet ${ }^{8}$, A Gerard 9 , J Beytout ${ }^{10}$, A Abergel $^{11}$, M Wallon ${ }^{12}$, D A Vuitton ${ }^{2,3}$, R Piarroux ${ }^{5}$, the FrancEchino network ${ }^{13}$ \\ 1. Aix-Marseille University, INSERM-IRD-AMU UMR 912, Marseille, France \\ 2. Franche-Comté University, CNRS UMR 6249, Besançon, France \\ 3. WHO Collaborating Centre for Prevention and Treatment of Human Echinococcosis, University Hospital Jean Minjoz, \\ Department of digestive surgery, Besançon, France \\ 4. University Hospital Jean Minjoz, Department of biochemistry, Besançon, France \\ 5. Aix-Marseille University, UMR MD 3, Marseille, France \\ 6. Centre National de Référence Echinococcose alvéolaire, Department of parasitology, CHRU Jean Minjoz Besançon, France \\ 7. University Hospital Edouard Herriot, Department of hepatogastroenterology, Hospices civils de Lyon, Lyon, France \\ 8. University Hospital Brabois, Department of hepatogastroenterology, Nancy, France \\ 9. University Hospital Brabois, Department of intensive care, Nancy, France \\ 10. University Hospital G Montpied, Department of tropical medicine and infectious diseases, Clermont-Ferrand, France \\ 11. University Hospital Estaing, Department of hepatogastroenterology, Clermont-Ferrand, France \\ 12. University Hospital de la Croix Rousse, Institute of parasitology and medical mycology, Hospices civils de Lyon, Lyon, France \\ 13. Members of the network are listed at the end of the article.
}

Piarroux M, Gaudart J, Bresson-Hadni S, Bardonnet K, Faucher B, Grenouillet F, Knapp J, Dumortier J, Watelet J, Gerard A, Beytout J, Abergel A, Wallon M, Vuitton DA, Piarroux R, the FrancEchino network. Landscape and climatic characteristics associated with human alveolar echinococcosis in France, 1982 to 2007 . Euro Surveill. 2015;20(18):pii=21118. Available online: http://www.eurosurveillance.org/ViewArticle.aspx?Articleld=21118

Article submitted on 15 March 2014 / published on 07 May 2015

Human alveolar echinococcosis (AE) is a severe hepatic disease caused by Echinococcus multilocularis. In France, the definitive and intermediate hosts of E. multilocularis (foxes and rodents, respectively) have a broader geographical distribution than that of human AE. In this two-part study, we describe the link between AE incidence in France between 1982 and 2007 and climatic and landscape characteristics. National-level analysis demonstrated a dramatic increase in $\mathrm{AE}$ risk in areas with very cold winters and high annual rainfall levels. Notably, 52\% (207/401) of cases resided in French communes (smallest French administrative level) with a mountain climate. The mountain climate communes displayed a 133 -fold ( $95 \%$ $\mathrm{Cl}$ : 95-191) increase in $\mathrm{AE}$ risk compared with communes in which the majority of the population resides. A case-control study performed in the most affected areas confirmed the link between AE risk and climatic factors. This arm of the study also revealed that populations residing in forest or pasture areas were at high risk of developing $A E$. We therefore hypothesised that snow-covered ground may facilitate predators to track their prey, thus increasing $E$. multilocularis biomass in foxes. Such climatic and landscape conditions could lead to an increased risk of developing $A E$ among humans residing in nearby areas.

\section{Introduction}

Echinococcus multilocularis is a cestode parasite that exhibits a dixenic life cycle involving circulation between canids and rodents. In France, the
E. multilocularis sylvatic life cycle involves foxes (the main definitive host) and rodents such as Arvicola terrestris, Microtus arvalis, $M$. agrestis or Ondatra zibethicus (the main intermediate hosts). Humans represent an aberrant host of the parasite, although they sometimes become infected with $E$. multilocularis larvae after ingesting parasite oncospheres. When $E$. multilocularis infects humans, E. multilocularis metacestode cells proliferate in the liver and eventually lead to alveolar echinococcosis (AE), a rare but severe hepatic disease resembling a slow-growing liver cancer [1].

A study by the EurEchinoReg network showed that 235 of 559 (42\%) European AE cases reported from 1982 to 2000 were observed in France [2]. Since 2000, the French registry of human $A E$ cases has been maintained by the FrancEchino network. In total, 407 human cases were identified from 1982 to 2007 [3]. In France, for this period, high-risk areas included the Massif Central and north-eastern regions of the country (Figure 1), where most cases either resided in rural communes (smallest French administrative level) or resided in towns but worked as farmers or tended gardens [3].

Although behavioural [3-8] and genetic [9-11] elements have been identified as risk factors of human AE, they largely fail to explain the geographical distribution of the disease. For instance, in China, specific landscapes, such as alpine meadows, are associated with an increased prevalence of human $A E[8,12]$. In Europe and especially in France, an increase in the proportion of grassland is associated with vole density outbreaks. 
Location of human alveolar echinococcosis cases with regard to elevation (A), population density (B) and climate type (C), France, $1982-2007(\mathrm{n}=401)$

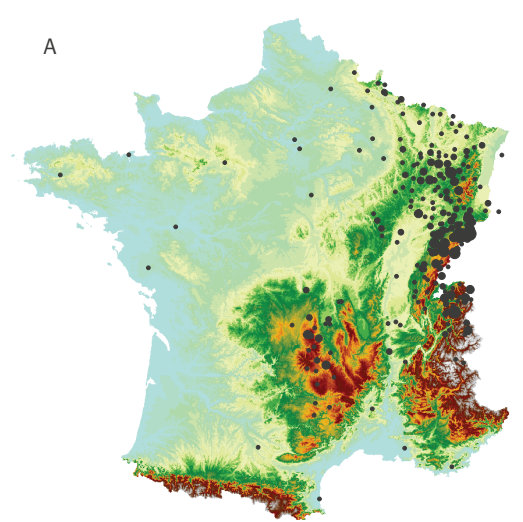

Elevation

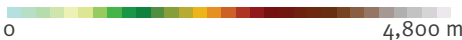

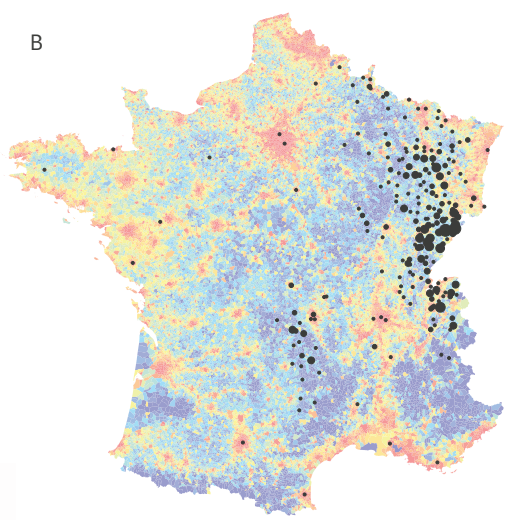

Population density

$0 \quad 10 \quad 50 \quad 100 \quad 1750$ habitants $/ \mathrm{km}^{2}$

Cumulative incidence from 1982 to 2007 (per canton)

i 5 io

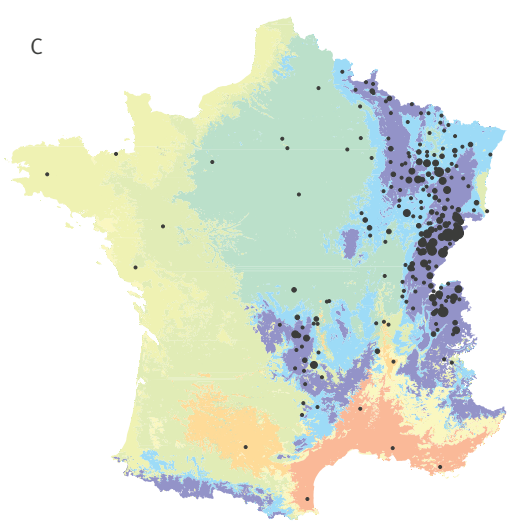

Climate type as defined by Joly et al. - Mountain

- Semi-continental and mountain margins

- Degraded oceanic of central and northern plains

- Altered oceanic

True oceanic

Altered Mediterranean

- South-west basin

True Mediterranean

Panel A illustrates that elevation is not the main factor associated with alveolar echinococcosis (AE) distribution. Panel B shows that cases were not located in densely inhabited areas. Panel C illustrates that AE cases were located in areas with a cold climate.

Joly et al. [21] described the types of climate as follows: Type 1 is characterised by a high number of rainy days, high cumulative precipitation levels, minimal average temperature, maximal number of days with temperatures $<-5^{\circ} \mathrm{C}$, minimal number of days with temperatures $30^{\circ} \mathrm{C}$, maximal interannual variability of rainfall in July and maximal interannual variability of temperatures in January and July. Type 2 is a transition from Type 1 to Type 3. Type 2 is characterised by cold January temperatures, slightly lower precipitation levels and less frequent precipitation than Type 1, and a low ratio between autumn and summer rainfall levels. Type 3 is characterised by intermediate temperatures and low precipitation levels, especially during the summer. For Type 3, the interannual variability of rainfall is minimal, while the interannual variability of temperature is high. Other climate types were of little interest regarding AE incidence patterns and were mostly characterised by warmer winter temperatures.

For ethical reasons, case locations are shown at the canton level (fourth French administrative division).

Dietary specialisation has been described in foxes during these outbreaks leading to an increase in the burden of $E$. multilocularis in foxes [13-15]. Nevertheless, human $A E$ case distribution does not correlate with that of grasslands, foxes or rodents. In particular, human $A E$ is very rarely diagnosed in western France, despite the apparent presence of favourable transmission factors regarding landscapes and hosts [13]. Thus, the key environmental and geographical factors associated with human $\mathrm{AE}$ transmission remain poorly understood.

In this study, we hypothesised that the completion of the sylvatic life cycle and transmission of the parasite from the animal hosts to humans depend on the climatic and landscape conditions. We first assessed the association between human AE cases and environmental data at a national scale in France. In the French regions with the highest $A E$ incidence rates, we then compared the habitat environment of $A E$ cases with that of randomly selected residences at a local scale.

\section{Methods}

This study included all AE cases diagnosed in France from 1982 to 2007. The analyses were performed in two parts. First, at the national level, we assessed AE cumulative incidence in each commune, considering several demographic and environmental variables (e.g. elevation, landscape and climate). France is divided into five nested administrative levels (listed from largest to smallest geographical divisions: régions, départements, arrondissements, cantons and communes). Second, we conducted a case-control study in the nine most affected French départements to compare case habitats (in terms of elevation, landscape and climate) with randomly selected control habitats at various buffer sizes (i.e. circular areas centred over each habitat with a $500 \mathrm{~m}, 1000 \mathrm{~m}, 1500 \mathrm{~m}$ and $2000 \mathrm{~m}$ radius $[12,16])$. 


\section{Data acquisition}

\section{Case definition and data collection}

Cases were defined as patients with compatible clinical and epidemiological histories and imaging findings or positive specific serology for $A E$.

Case data were obtained from the FrancEchino network registry, which is supported by the French Institute for Public Health Surveillance (Institut de Veille Sanitaire, InVS). This population-based registry actively collects French AE case data as previously described [17].

Addresses of the cases were registered in a separate anonymous database according to French regulation (Comité National pour l'Informatique et les Libertés and Comité de Protection des Personnes) in the context of biomedical research [18].

We interviewed all pathologists, parasitologists, public university hospital pharmacy staff (who are the only people allowed to deliver albendazole or mebendazole for AE treatment in France) and medicine, radiology and abdominal surgery hospital department staff who treat $A E$ patients.

\section{Environmental data}

Demographic data were obtained from the French National Institute of Statistics and Economic Studies (INSEE) [19].

Land cover data were obtained from the European Commission programme to coordinate information on the environment (CORINE) land cover (CLC) 2006 map [20]. Pixel size was $25 \mathrm{~m} \times 25 \mathrm{~m}$. The $44 \mathrm{CLC}$ classes are typically categorised into five groups (agricultural areas, forests and semi-natural areas, artificial surfaces, wetlands, water bodies and open spaces without vegetation). We chose to detail the group 'agricultural areas' into three subgroups (arable and permanent cultures, heterogeneous agricultural areas and pastures) because these types of landscape environments play an important role in the life cycle of foxes and voles, as observed in China and eastern France $[12,13,15,16]$. We also subdivided the group 'forests and semi-natural areas' into three subgroups (broad-leaf and mixed forest, coniferous forest and shrub and herbaceous vegetation). The group 'artificial surfaces' was left unmodified, while the three remaining groups were recategorised into the class 'other'. For each analysed territory (either commune or buffer around habitats), we calculated the percentage of each CLC class and the mode, i.e. the CLC class covering the largest part of the territory.

Climate data were obtained from Joly et al. [21]. Briefly, the authors provided a set of 15 raster climate maps (with a precision of $250 \mathrm{~m} \times 250 \mathrm{~m}$ ) that we used to extract 14 variables as follows: annual mean temperature, number of cold days (with minimum temperature less than $-5^{\circ} \mathrm{C}$ ), number of warm days (with maximum temperature above $30^{\circ} \mathrm{C}$ ), difference in mean temperature between January and July, cumulative annual precipitation, number of rainy days in January, number of rainy days in July, difference in precipitation levels between January and the entire year, difference in precipitation levels between July and the entire year, interannual variability in temperature in January, interannual variability in temperature in July, interannual variability in precipitation in January, interannual variability in precipitation in July, (September+October) precipitation/July precipitation, and an integrative climate typology classifying French climates into eight types (Type 1: mountain; Type 2: semi-continental and mountain margins; Type 3: degraded oceanic of central and northern plains; Type 4: altered oceanic; Type 5: true oceanic; Type 6: altered Mediterranean; Type 7: south-west basin; and Type 8: true Mediterranean) (Figure 1). For each analysed territory (commune or buffer around habitats), we calculated the percentage covered by each variable modality and extracted the mode of each variable.

Elevation data were obtained from the Shuttle Radar Topography Mission (ArcGIS data and maps CD-ROM, Environmental Systems Research Institute (ESRI), Redland, CA, United States) with a precision of $100 \mathrm{~m}$ $\mathrm{x} 100 \mathrm{~m}$.

Selection of control residences

Control residences were selected from the non-professional French telephone directory by applying a computerised algorithm based on a uniform distribution on page, column and line. We randomly selected two addresses from 10,000 inhabitants in each of the nine most affected départements, i.e. the départements with an $A E$ incidence rate greater than the upper limit of the $95 \%$ confidence interval $(\mathrm{CI})$ of the mean incidence rate.

\section{Geographical location}

Address location at the time of diagnosis was determined using Geoportail [22]. We confirmed the location data using the cadastre registry [23].

When the location of a case (or control) residence could not be accurately determined (e.g. in a hamlet with no street name and no house number), the place of residence was arbitrarily selected as the centre of the corresponding inhabited area. Therefore, the maximum imprecision for case and control residences was less than $500 \mathrm{~m}$.

Cases with insufficient address data were excluded from the buffer analysis.

\section{Statistical analysis}

Alveolar echinococcosis distribution in communes at a national scale

Global spatial clustering analysis of AE-affected communes was performed using the Moran's I coefficient. 
The relationship between the AE case number of each French commune and each covariable was subjected to univariate analysis using a general linear model (GLM). Univariate quasi-Poisson models were constructed using the log population of communes as an offset and considering overdispersion patterns. The correlations between covariables were assessed using the Spearman coefficient. Only significant variables at $95 \%$ risk were retained for further analyses.

Multivariate analyses were performed according to the methodology developed by Breiman (classification and regression tree (CART) analysis) [24] to classify the communes based on AE risk. This methodology only retains the main covariates among the collinear variables, thereby generating a tree in which the terminal nodes represent classes of communes with common characteristics. The resulting classification was analysed using a quasi-Poisson GLM to estimate standardised incidence ratios.

Case-control study of habitats at a local scale

A univariate comparison of the buffers surrounding case and control habitats was performed using the Wilcoxon test for quantitative variables and the Fisher's exact test for categorical variables. Only significant variables were retained for further analyses.

Multivariable analyses were carried out using the hierarchical ascendant classification on the multiple correspondence analysis results. We determined the most homogeneous land cover and climate groups independent of the $\mathrm{AE}$ status of the residents within the buffers [25], using v.test to describe how each variable influences each category. The AE incidence rates of the resulting classes were then analysed using a logistic model. The associated odds ratios were then estimated.

Statistical analysis was performed using $R$ 3.0.2 software ( $R$ foundation for statistical computing, Vienna, Austria) with the Factominer and R-PART packages. The regression models were compared using Akaike information criterion. The test results were interpreted applying a fixed threshold at $a=0.05$.

\section{Cartography}

Spatial representation of the $\mathrm{AE}$ data was generated using ArcGIS 9.3 software. Simple Voronoï maps were used to enhance the clarity of the buffer categories and respect ethical concerns. The commune-level results are shown aggregated at the canton level for ethical reasons.

\section{Results}

\section{Alveolar echinococcosis distribution at a}

\section{national scale}

The commune of residence was identified for 389 of the 407 cases registered by the FrancEchino network between 1982 and 2007. At a national level, the communes of case residences were found to be clustered (Moran's I index $=0.6(Z=26.48, p<0.01)$ ).

Marked correlations were often found between variables, especially when belonging to the same group. For example, most correlation coefficients between demographic variables were>0.7, most correlation coefficients between altitude variables were $>0.7$, and at least one correlation coefficient was >0.5 in-between climate variables. In contrast, the land cover variables exhibited weaker intragroup correlations (<0.5). Additionally, the demographic variables, the altitude variables and eight of the 15 climate variables displayed overdispersion.

The GLM univariate analysis of AE-affected and nonaffected communes revealed a disparity for all variables except ((September + October) precipitation/July precipitation) and two land cover classes (heterogeneous agriculture and other).

Multivariable CART analysis showed that the climate variables provided the best discrimination between $A E$ and non-AE communes (Figure $2 A$, Table 1). Five classes of communes were subsequently defined. Class 1 , which represented $52 \%(n=201)$ of the cases but only $3 \%$ of the French population $(1,833,904$ inhabitants), comprised communes with a mountain climate (i.e. Type 1 climate, as defined by Joly et al. [21]). The standardised incidence ratio was 133 (95\% Cl: 95-191), compared with Class 5 (reference class). Class 5 represented $84 \%$ of the French population $(46,201,895$ inhabitants) but only 38 (9.8\%) cases. This class comprised communes characterised by climate types other than mountain or semi-continental and a mean annual temperature above $9.4^{\circ} \mathrm{C}$. The other classes exhibited intermediate climatic conditions (Figure 2).

Case-control study of the respective residences in the nine most affected French départements Of the $407 \mathrm{AE}$ cases, 270 lived in the nine most affected départements. The commune of residence was identified for 266 of these cases. A precise address (i.e. hamlet or street name and number) was available for 196 of these cases. Cases with a precise address did not significantly differ from cases with non-specific addresses regarding mean age, sex ratio, clinical status or occupation (data not shown). The 74 cases without a precise address were excluded from the buffer analyses. A total of 539 control habitats were selected.

At this local scale $(500 \mathrm{~m}, 1,000 \mathrm{~m}, 1,500 \mathrm{~m}$ and $2,000 \mathrm{~m}$ buffer radii as well as the communal level), the best model corresponded to a $500 \mathrm{~m}$ buffer radius and yielded five categories of habitat surroundings based on the Akaike information criterion (Table 2). Compared with the reference category (Category 1), only Categories 4 and 5 were associated with a significant increase in $\mathrm{AE}$ risk (OR: $2.40,95 \% \mathrm{Cl}: 1.38-4.13$ and OR:2.72, 95\% Cl: 1.75-4.26, respectively) (Table 3). Category 4 consisted of habitats located in areas 


\section{FIGURE 2}

National-level classification of French communes where residents are at high risk of developing alveolar echinococcosis, $1982-2007$

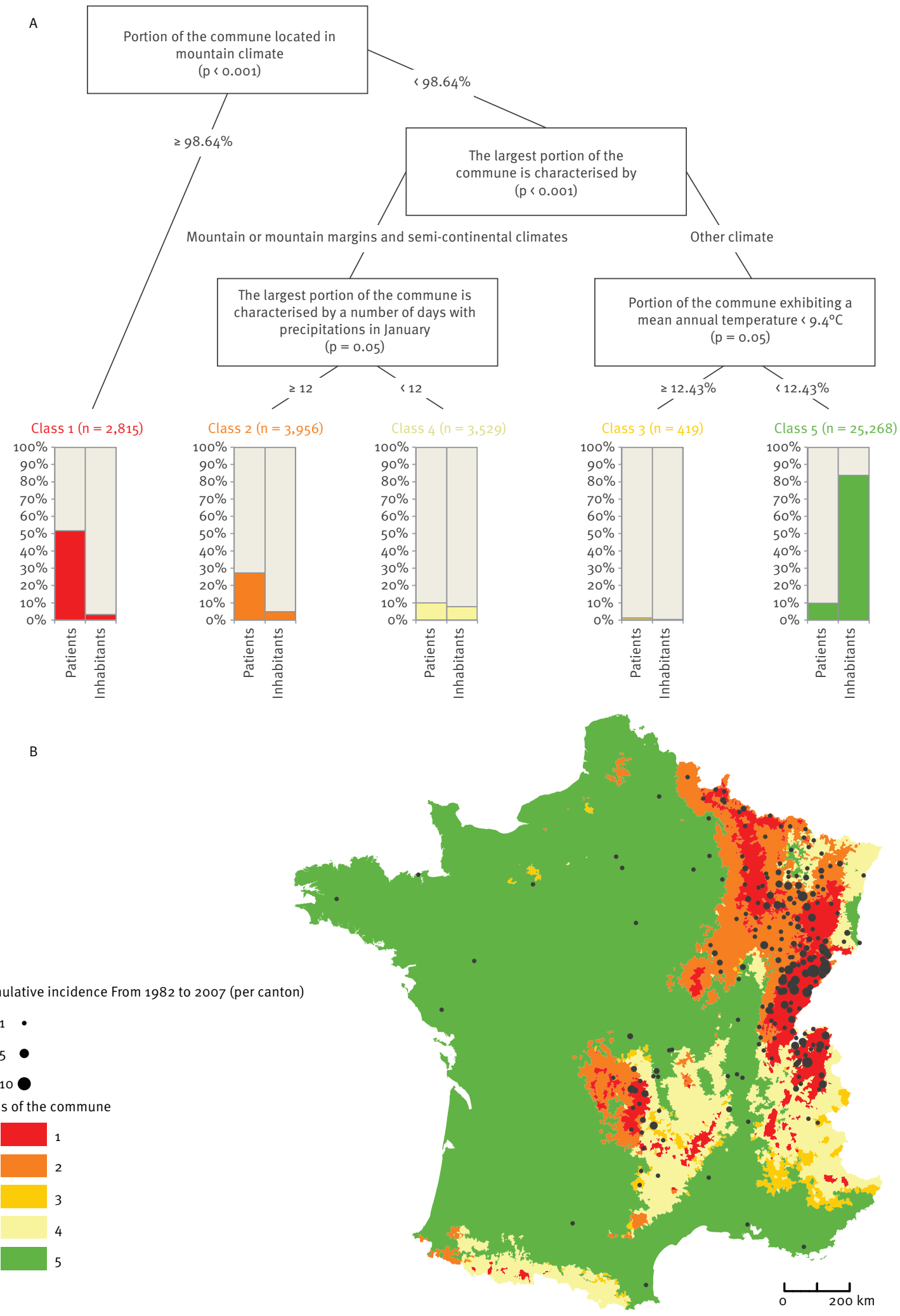

Panel A demonstrates the commune class analysis results. The terminal nodes of the classification and regression tree (CART) analysis results correspond to the five classes of commune. The percentage of cases (left side) and inhabitants (right side) residing in each class are indicated. Class 5 is the reference class, where most of the French population is located. In contrast, most of the alveolar echinococcosis cases were located in Class 1 and Class 2 communes. Localisation of these classes and the cumulative cases during 1982 to 2007 are shown in panel B. For ethical reasons, case locations are shown at the canton level (fourth French administrative division). 
TABLE 1

Classification of risk of alveolar echinococcosis in French communes at national level, 1982-2007

\begin{tabular}{|l|c|}
\hline Commune class & Standardised incidence ratio $(95 \% \mathrm{Cl})$ \\
\hline Intercept & $8.22 \times 10^{-7}\left(6.71 \times 10^{-7}-1.83 \times 10^{-6}\right)$ \\
\hline 1 & $133.26(91.97-199.77)$ \\
\hline 2 & $48.47(32.46-4.38)$ \\
\hline 3 & $28.52(8.51-71.99)$ \\
\hline 4 & $11.07(0.71-18.27)$ \\
\hline 5 & $1(\mathrm{NA})$ \\
\hline
\end{tabular}

$\mathrm{Cl}$ : confidence interval; NA: not applicable.

Each terminal node of the classification and regression tree (CART) analysis represented a class of French communes. Compared with Class 5, where most of the French population resides, persons residing in the communes of Classes 1,2 and 3 were at significantly higher risk of contracting alveolar echinococcosis. The communes of Class 1 exhibit a mountain climate. The communes of Class 2 exhibit a rainy semi-continental climate, while the communes of Class 3 exhibit a non-mountainous, noncontinental and cold climate.

Standardised incidence ratio for each commune class displayed in Figure 2A.

with the greatest slope and elevation levels as well as a land cover dominated by broad-leaf and mixed forests. Category 5 included habitats characterised by pastures. Both Category 4 and Category 5 were also characterised by a very cold ( $\geq 25$ days with cold temperature (less than $-5^{\circ} \mathrm{C}$ )) and humid (total annual precipitation $\geq 1,150 \mathrm{~mm}$ ) mountain climate. The spatial distribution of these categories of habitat environments is shown in Figure 3.

\section{Discussion}

In this study, we identified a significant association between climatic factors and human cases of $A E$ in France from 1982 to 2007 at national and local scales. The map indicating human AE cases and the principal climates in France clearly highlights this association (Figure 1). Nevertheless, we observed some discrepancies, such as a low incidence of $A E$ in the southern mountainous areas of France despite the cold climate. When analysing the data at the national and local scales, we were able to include additional parameters such as rainfall effects and land cover composition. Applying this analysis, we also observed an almostperfect fit between geographical and epidemiological data. Overall, our findings indicate that an increased risk of contracting $A E$ in France is associated with residing in areas exhibiting the coldest winters, marked rainfall levels throughout the year and, to a lesser degree, forest and pasture land covers. Areas exhibiting a mountain climate that did not report cases of human $A E$, such as the southern Alps, were characterised by winters with relatively lower levels of rain and snow precipitation.
Interestingly, the distribution area of the principal hosts involved in the $E$. multilocularis life cycle in France extends far beyond the high-risk areas shown in our study. Indeed, foxes and E. multilocularis-permissive rodents are found in every rural area countrywide [13]. Therefore, climate does not act only by limiting the distribution of the intermediate and definitive host populations.

Our results show that $A E$ high-risk areas are much more associated with winter temperatures and high precipitation levels than summer climatic conditions. Indeed, residing in the majority of French territories with an oceanic climate, cool summer temperatures and temperate winters was not associated with high human incidence rates of the disease. This association between $A E$ incidence and residing in areas where winters are cold and humid corroborates previous studies conducted in China [26] and France [27]. Furthermore, several studies have highlighted a link between climatic conditions and $E$. multilocularis biomass in foxes. In Germany, foxes living in agricultural regions with high levels of precipitation harboured the greatest parasite burden $[28,29]$. Furthermore, the degree of fox infection was negatively associated with annual temperatures in the German federal state of Saxony-Anhalt [30]. The mechanism by which cold and humid winters enable successful completion of the parasite life cycle remains to be explained. One hypothesis demonstrated in Alaska suggests that snow acts as a parasite life cycle facilitator [31]. The overall distribution of $A E$ observed throughout the northern hemisphere supports this hypothesis [2,32]. Regular snowy periods during the winter may greatly affect the predator-prey relationship by assisting foxes to capture rodents and thus increasing the degree of fox infection during late winter and early spring [33]. Climatic conditions may also support the conservation of $E$. multilocularis eggs in the environment. Although cold temperatures do not affect egg viability, hot and dry episodes during the summer can easily destroy the eggs [34]. Therefore, regions exhibiting cold winters, cool summers and a humid climate throughout the year may best support the $E$. multilocularis life cycle. The relatively low incidence of human AE in the southern Alps and eastern Pyrenees may be due to the relatively hot and dry summers, despite the cold winters exhibited in these regions. Additionally, these mountain regions are fragmented with deep valleys, which reduce the amount of contact between different fox populations. This may support autochthonous $A E$ foci, as shown in northern Italy [35], or impede infected foxes from importing the parasite following the extinction of local $E$. multilocularis populations. In southern France, only the western part of the Pyrenean mountains and a few patches in the southern Alps and Massif Central exhibit climatic conditions conducive to $A E$ transmission. In these areas, $A E$ transmission may not be perennial because the foci are relatively small and there is limited host exchange between the foci and other permissive areas [36]. 
TABLE 2

Classification of land cover and climate in buffers of a $500 \mathrm{~m}$ radius around habitats in the nine départements in France most affected by alveolar echinococcosis, 1982-2007

Category 1 (48 patients, 193 controls)

Mean annual temp $\geq 9.4$ and $<10.4^{\circ} \mathrm{C}$

Number of days with cold temp $\left(<-5^{\circ} \mathrm{C}\right) \geq 14$ and $<25$

Mean elevation $>304 \mathrm{~m}$

Number of rainy or snowy days in January $\geq 13$

Total annual precipitation $\geq 940$ and $<1,150 \mathrm{~mm}$

Total annual precipitation $\geq 800$ and $<940 \mathrm{~mm}$

Range elevation $<61 \mathrm{~m}$

Number of rainy days in July $\geq 9$

Mountain margins and semi-continental climate (type 2)

Difference between July and January mean temp. $\geq 14.7$ and $<15.7^{\circ} \mathrm{C}$

Category 2 (4 patients, 16 controls)

Total annual precipitation $\geq 710$ and $<800 \mathrm{~mm}$

Difference between July and January mean temp. $\geq 14.7$ and $<15.7^{\circ} \mathrm{C}$

Number of rainy days in July $\geq 6$ and $<7$

Degraded oceanic climate (type 3 )

Altered oceanic climate

Category 3 (45 patients, 179 controls)

Difference between July and January mean temp. $\geq 16.9^{\circ} \mathrm{C}$

Mean annual temp. $\geq 10.4$ and $<11.4^{\circ} \mathrm{C}$

Number of days with hot temp. $\left(>30^{\circ} \mathrm{C}\right) \geq 15$ and $<23$

Number of rainy days in July $\geq 8$ and $<9$

Number of rainy or snowy days in January $\geq 9$ and $<11$

Number of days with cold temp. $\left(<-5^{\circ} \mathrm{C}\right) \geq 14$ and $<25$

Category 4 (31 patients, 52 controls)

Range elevation $\geq 124$ and $<230 \mathrm{~m}$

Mean slope $\geq 12.5 \%$

Range slope $\geq 29.9$

Range elevation $\geq 230 \mathrm{~m}$

Number of days with cold temp. $\left(<-5^{\circ} \mathrm{C}\right) \geq 25$

Range slope $\geq 19.3$ and $<29.9$

Total annual precipitation $\geq 1,150 \mathrm{~mm}$

Broad-leaf and mixed forest

Mean slope $\geq 6.7$ and $<12.5$

Mountain climate (type 1)

Category 5 (67 patients, 99 controls)

Mean annual temp. $<9.4^{\circ} \mathrm{C}$

Number of days with cold temp. $\left(<-5^{\circ} \mathrm{C}\right) \geq 25$

Difference between July and January mean temp. $\geq 15.7$ and $<16.9^{\circ} \mathrm{C}$

Mountain climate (type 1)

Number of days with hot temp. $\left(>30^{\circ} \mathrm{C}\right)<4$

Mean elevation $\geq 740 \mathrm{~m}$

Number of days with hot temp. $\left(>30^{\circ} \mathrm{C}\right) \geq 4$ and $<9$

Number of rainy days in July $\geq 9$

Total annual precipitation $\geq 1,150 \mathrm{~mm}$

Pastures

17.147148

13.488042

12.684608

9.087546

8.942823

8.914855

7.851899

7.56979

6.171585

6.088195

9.863617

7.757912

6.857535

6.857535

6.6954

16.971824

14.648773

14.494255

12.257087

6.288545

5.616076

13.688276

13.031426

10.958377

9.745691

8.943433

8.873805

8.865216

8.100202

7.5422

7.313873

20.812435

13.021636

10.621712

9.925993

9.340607

9.256912

8.237715

7.154073

6.75911

5.155408

Entries In bold are variables with a v.test $>10$.

a v.test describes how the variable influences a category. It specifies how much the proportion of the modality of a variable within the category differs from the proportion in other categories. A variable modality was considered to be specific for a category when |v.test| $>3$ with $p<0.01$. For more readability, we only show the variables with the most influence producing a positive impact on the category. 


\section{TABLE 3}

Odds ratios associated with land cover and climate classification of the $500 \mathrm{~m}$-radius buffers in the nine French départements most affected by alveolar echinococcosis, 1982-2007

\begin{tabular}{|l|c|c|}
\hline $\begin{array}{l}\text { Category of habitat } \\
\text { surroundings }\end{array}$ & $\begin{array}{c}\text { Number of patients/ } \\
\text { controls }\end{array}$ & Odds ratio $(95 \% \mathrm{Cl})$ \\
\hline 1 & $48 / 193$ & $1(\mathrm{NA})$ \\
\hline 2 & $4 / 16$ & $1.01(0.28-2.89)$ \\
\hline 3 & $45 / 179$ & $1.01(0.64-1.59)$ \\
\hline 4 & $31 / 52$ & $2.40(1.39-4.13)$ \\
\hline 5 & $67 / 99$ & $2.72(1.75-4.26)$ \\
\hline
\end{tabular}

$\mathrm{Cl}$ : confidence interval; NA: not applicable.

At a local scale in China, Pleydell et al. observed marked variations in $\mathrm{AE}$ prevalence between villages located less than $10 \mathrm{~km}$ apart in Zhang County, Ningxia, China, in an area spanning about 4,000 $\mathrm{km}^{2}$ [16]. Moreover, human $\mathrm{AE}$ cases in France are irregularly dispersed, as hotspots of higher endemicity were observed at a finer scale within hyperendemic clusters [37]. Our study shows that the heterogeneous pattern of human $A E$ incidence correlates with climate and land cover distribution at a local scale. AE incidence is also closely associated with human life habits, which change over time. Depending on the country, the most frequent individual AE risk factors include a person's sex, region of residence, agricultural or pastoral occupation, dog ownership and gardening practices [3,4,6-8]. In neighbouring Germany, the highest-risk behaviour associated with $A E$ was farming, and gardeners were only at risk if they cultivated leaf or root vegetables [4]. These behavioural factors may partially explain the heterogeneous pattern of human AE distribution.

Our study of human AE cases complements investigations focusing on the sylvatic life cycle of the parasite [12,36-38]. From 2001 to 2005 , in an area of only $900 \mathrm{~km}^{2}$ of the French Ardennes, Guislain et al. observed a north/south gradient of infestation among foxes ranging from $20 \%$ to $80 \%$, respectively [38]. In four zones in the canton of Zurich in Switzerland, approximately $1 \mathrm{~km}$ in radius separated by less than $15 \mathrm{~km}$, the prevalence of E. multilocularis in foxes varied from $11.2 \%$ (95\% Cl: $12.7-27.2)$ to $60.7 \%$ (95\% $\mathrm{Cl}$ : 40.6-78.5) [39]. The populations of intermediate hosts, such as voles, fluctuate partially due to human behaviour [40] and thereby act as a metapopulation, as observed in China by Pleydell et al. [16]. This observation therefore explains the observed variability in voles' contribution to fox alimentation and subsequent variability in fox infestation [12].

We acknowledge that this study has several limitations. First, our approach addressed the risk of contracting AE among humans over an extended time

\section{FIGURE 3}

Map of the land cover and climate classification of the $500 \mathrm{~m}$-radius buffers in the nine French départements most affected by alveolar echinococcosis, 1982-2007
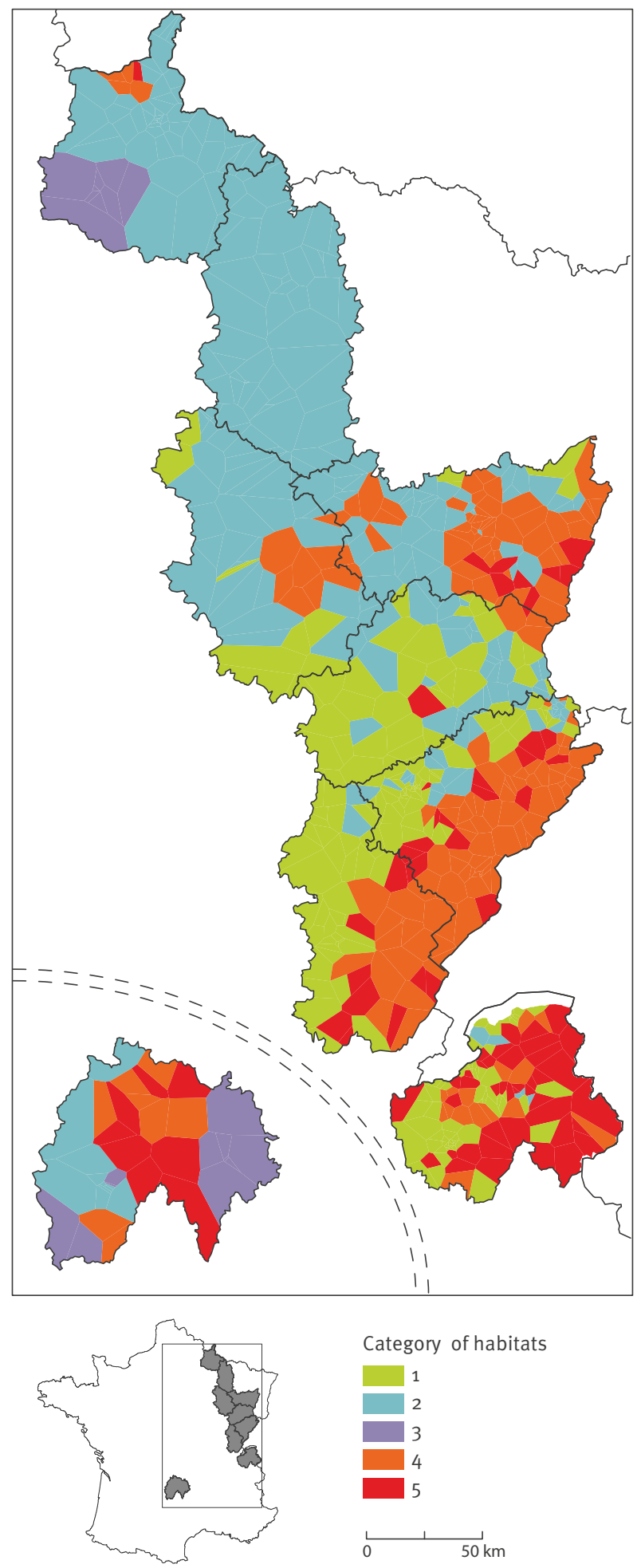

Hierarchical clustering on principle components analysis determined five categories of habitats. Significant disparities were observed between the residence location of cases and controls even at this fine scale. Category 1 is the reference class (habitats where residents were least at risk of developing alveolar echinococcosis (AE).

Persons living in Category 4- and 5-type habitats were at higher risk of contracting AE compared with individuals residing in the rest of the area (see Tables 2 and 3 ). For ethical reasons, a Voronoï polygon map is shown instead of buffers. 
period in a relatively expansive area. Due to the vast area and extended period, the human data are probably not $100 \%$ exhaustive. The process of data collection [17] was based on repeated inquiries with all health professionals potentially involved in case management, ranging from those diagnosing the disease to those delivering specific treatments. As $A E$ incidence is low in most regions of France, the disease is irregularly recognised by physicians, which may lead to under-diagnosis. However, diagnostic imaging and serological testing has greatly improved over the last few decades [41] and persistent misdiagnosis of such a chronic and severe disease is becoming less common. Additionally, if under-diagnosed cases minimised $A E$ incidence in some areas, it is unlikely that the subsequent bias would yield such a perfect fit between $A E$ cases and climatic conditions.

Second, as $A E$ exhibits a long incubation period, i.e. between five and 15 years [1], the environment of cases may have changed between the dates of infection and diagnosis. However, previous analysis revealed that way of life and lifelong residence location of the same group of cases was markedly stable [3]. In France, climate and rural landscape change gradually over the course of several human generations. Therefore, the area associated with an increased risk of disease transmission to humans likely remained rather stable during the study period and will not radically change in the near future. It should, however, be emphasised that omitted parameters, such as fox population and the behaviour of humans and foxes (e.g. increase in urban fox populations), may also play a role in disease transmission. Combes et al. [42] have reported E. multilocularis infection in foxes far west of documented endemic areas in France (eastern and central France), even if parasitic loads observed in foxes in western areas were low compared with that in endemic areas of eastern France [43]. Therefore, as AE epidemiology is still evolving in France and Europe, it is important to continue diligent surveillance of human and fox infestation.

\section{The FrancEchino Network}

Annecy: VITRAT Virginie. Besançon: BARDONNET Karine; BARTHOLOMOT Brigitte; BEURTON-CHATAIGNER Isabelle; BLAGOSKLONOV Oleg; BRESSON-HADNI Solange; BRIENTINI Marie Pascale; CAPPELLE Sylvie; DELABROUSSE Eric; DI MARTINO Vincent; EVRARD Philippe; FELIX Sophie; GIRAUDOUX Patrick; GRENOUILLET Frédéric; HEYD Bruno; KANTELIP Bernadette; KNAPP Jenny; KOCH Stéphane; MANTION Georges; MILLON Laurence; RAOUL Francis; RICHOU Carine; VANLEMMENS Claire; VUITTON Lucine; VUITTON Dominique Angèle. Bourg en Bresse: PROST Patricia. Charleville Mezière: GODET Claire. Clermont Ferrand: ABERGEL Armand; BEYTOUT Jean; CAMBON Monique. Dijon: BESANCENOT Jean François; CUSENIER Bernadette; HILLON Patrick; MINELLO Anne. Grenoble: FAURE Odile; LETOUBLON Christian. Lyon: CHYDERIOTYS Georges; DUMORTIER Jérôme; GUILLAUD Olivier; PARTENSKY Christian; RABODONIRINA Meja; WALLON Martine. Marseille: PIARROUX Martine; PIARROUX Renaud. Metz: CHATELAIN Eric; JOHANN Marc; RAABE Jean-Jacques. Mulhouse: SONDAG Daniel. Nancy:
GERARD Alain; LETRANCHANT Lorraine; MACHOUART Marie; WATELET Jérôme. Paris: FARGES Olivier; SAMUEL Didier. Reims: CHEMLA Cathy; DELATTRE Jean Francois. Rodez: GUERIN Bruno. Saint Ouen l'Aumône: DEBRUYNE Monique. Strasbourg: ABOU-BACAR Ahmed; AUDET Maxime; HANSMANN Yves; LEFEBVRE Nicolas. Thonon: LI Véronique. Vesoul: ALBY-LEPRESLE Blandine.

\section{Acknowledgments}

We thank Sandra Moore for English revision.

Conflict of interest

None declared.

Authors' contributions

MP, JG and RP conceived and designed the surveys used in this article, MP and JG conducted statistical analyses, MP, $J G, B F, D A V$ and RP contributed to the interpretation of data and wrote the first draft, and all others authors contributed to collecting data, revised the article critically and approved the final version.

\section{References}

1. Pawlowski Z, Eckert J, Vuitton D, Ammann R, Kern P, Craig P, et al. Echinococcosis in humans: clinical aspects, diagnosis and treatment. In: WHO/OIE manual on echinococcosis in humans and animals: a public health problem of global concern. Eckert J, Gemmel MA, Meslin FX, Pawlowski ZS editors. Paris/ Geneva: World Organisation for Animal Health/World Health Organization; 2001. p. 20-72.

2. Kern P, Bardonnet K, Renner E, Auer H, Pawlowski Z, Ammann RW, et al. European echinococcosis registry: human alveolar echinococcosis, Europe, 1982-2000. Emerg Infect Dis. 2003;9(3):343-9. http://dx.doi.org/10.3201/eido903.020341 PMID:12643830

3. Piarroux M, Piarroux R, Knapp J, Bardonnet K, Dumortier J, Watelet J, et al. Populations at risk for alveolar echinococcosis, France. Emerg Infect Dis. 2013;19(5):721-8. http://dx.doi. org/10.3201/eid1905.120867 PMID:23647623

4. Kern P, Ammon A, Kron M, Sinn G, Sander S, Petersen LR, et al. Risk factors for alveolar echinococcosis in humans. Emerg Infect Dis. 2004;10(12):2088-93. PMID:15663843

5. Wang Q, Qiu J, Yang W, Schantz PM, Raoul F, Craig PS, et al. Socioeconomic and behavior risk factors of human alveolar echinococcosis in Tibetan communities in Sichuan, People's Republic of China. Am J Trop Med Hyg. 2006;74(5):856-62. PMID:16687693

6. Kreidl P, Allerberger F, Judmaier G, Auer H, Aspöck H, Hall AJ. Domestic pets as risk factors for alveolar hydatid disease in Austria. Am J Epidemiol. 1998;147(10):978-81. http://dx.doi. org/10.1093/oxfordjournals.aje.a009388 PMID:9596476

7. Stehr-Green JK, Stehr-Green PA, Schantz PM, Wilson JF, Lanier A. Risk factors for infection with Echinococcus multilocularis in Alaska. Am J Trop Med Hyg. 1988;38(2):380-5. PMID:3354771

8. Craig PS, Giraudoux P, Shi D, Bartholomot B, Barnish G, Delattre $P$, et al. An epidemiological and ecological study of human alveolar echinococcosis transmission in south Gansu, China. Acta Trop. 2000;77(2):167-77. http://dx.doi.org/10.1016/ So001-706X(00)00134-0 PMID:11080507

9. Yang YR, Ellis M, Sun T, Li Z, Liu X, Vuitton DA, et al. Unique family clustering of human echinococcosis cases in a Chinese community. Am J Trop Med Hyg. 2006;74(3):487-94 PMID:16525111

10. Zhang S, Penfornis A, Harraga S, Chabod J, Beurton I, Bresson-Hadni S, et al. Polymorphisms of the TAP1 and TAP 2 genes in human alveolar echinococcosis. Eur J Immunogenet. 2003;30(2):133-9. http://dx.doi.org/10.1046/j.13652370.2003.00375.x PMID:12648282

11. Vuitton DA, Zhang SL, Yang Y, Godot V, Beurton I, Mantion G, et al. Survival strategy of Echinococcus multilocularis in the human host. Parasitol Int. 2006;55 Suppl:S51 55.

12. Giraudoux P, Raoul F, Pleydell D, Li T, Han X, Qiu J, et al. Drivers of Echinococcus multilocularis transmission in China: 
small mammal diversity, landscape or climate? PLoS Negl Trop Dis. 2013;7(3):e2045. http://dx.doi.org/10.1371/journal. pntd.0002045 PMID:23505582

13. Tolle F, Raoul F, Tourneux F. Modéliser et représenter la vulnérabilité paysagère dans un contexte épidémiologique : les hôtes intermédiaires d'Echinococcus multilocularis. [Modelling and representing landscape vulnerability in epidemiological context: Echinococcus multilocularis intermediate hosts]. Colloque International de Géomatique et d'Analyse Spatiale [2nd Spatial Analysis and GEOmatics conference], 11-13 September 2006, Strasbourg, France. Théoriser et modéliser pour aménager (ThéMA); 2006. [Accessed 16 Feb 2014]. French. Available from: http:// cddthema.univ-fcomte.fr/doc_num.php?explnum_id=344

14. Pesson B, Carbiener R. Ecologie de l'échinococcose alvéolaire en Alsace: le parasitisme du Renard roux (Vulpes vulpes L.). [Ecology of alveolar echinococcosis in Alsace: parasitism in red fox (Vulpesvulpes L.)]. Bulletin d'écologie. 1989;20(4):295-301. French.

15. Raoul F, Depierre V, Scheifler R, Mass R, Petavy AF, Vuitton D, et al. Landscape effect on Echinococcus multilocularis winter prevalence in foxes in the Jura massif, France. Helminthologia. 1999;36:48.

16. Pleydell DRJ, Yang YR, Danson FM, Raoul F, Craig PS, McManus $D P$, et al. Landscape composition and spatial prediction of alveolar echinococcosis in southern Ningxia, China. PLoS Negl Trop Dis. 2008;2(9):e287. http://dx.doi.org/10.1371/journal. pntd.0000287 PMID:18846237

17. Piarroux M, Piarroux R, Giorgi R, Knapp J, Bardonnet K, Sudre B, et al. Clinical features and evolution of alveolar echinococcosis in France from 1982 to 2007: results of a survey in 387 patients. J Hepatol. 2011;55(5):1025-33. http://dx.doi. org/10.1016/j.jhep.2011.02.018 PMID:21354448

18. Commission Nationale Informatique et Libertés (CNIL). Méthodologie de référence pour les traitements de données personnelles opérés dans le cadre des recherches biomédicales. [Reference methodology for personal data processing in the context of biomedical research]. Paris: CNIL. [Accessed 11 Apr 2014]. French. Available from: http://www. cnil.fr/fileadmin/documents/declarer/mode_d-emploi/sante/ MR-001.pdf

19. Institut National de la Staistique et des Etudes Economiques (Insee). Résutats de l'inventaire communal 1998. [Results of the 1998 communal inventory]. Paris: Insee. [Accessed $11 \mathrm{Apr}$ 2014]. French. Available from: http://www.insee.fr/fr/ppp/ bases-de-donnees/donnees-detaillees/ic098/ico98.asp

20. European Environment Agency (EEA). Corine land cover 2006 raster data. Copenhagen: EEA. [Accessed 16 Feb 2014]. Available from: http://www.eea.europa.eu/data-and-maps/ data/corine-land-cover-2006-raster-2

21. Joly D, Brossard T, Cardot H, Cavailhes J, Hilal M, Wavresky P. Les types de climats en France, une construction spatiale. [Types of climates in France, a spatial construction]. Cybergeo: European Journal of Geography. 18 Jun 2010. [Accessed 16 Feb 2014 16]. French. Available from: http://cybergeo.revues. org $/ 23155$

22. Institut national de l'information géographique et forestière (IGN). Géoportail, le portail des territoires et des citoyens. Saint-Mandé: IGN. [Accessed 24 Apr 2015]. French. Available from: http://www.geoportail.fr

23. Ministère des Finances et des Comptes publics. Cadastre. gouv.fr. Paris: Ministère des Finances et des Comptes publics. [Accessed 24 Apr 2015]. French. Available from: http://www. cadastre.gouv.fr

24. Breiman L, Friedman JH, Olshen RA. Stone CJ. Classification and regression trees. Wadsworth Wadsworth statistics probability series. Belmont, CA: CRC Press; 1984.

25. Lê S, Josse J, Husson F. FactoMineR: an R package for multivariate analysis. J Stat Softw. 2008;25(1).

26. Zhou HX, Chai SX, Craig PS, Delattre P, Quéré JP, Raoul F, et al. Epidemiology of alveolar echinococcosis in Xinjiang Uygur autonomous region, China: a preliminary analysis. Ann Trop Med Parasitol. 2000;94(7):715-29. PMID:11144813

27. Aubert M, Jacquier P, Artois M, Barrat MJ, Basile AM. Le portage d'Echinococcus multilocularis par le renard (Vulpes vulpes) en Lorraine. Conséquences sur la contamination humaine. [Echinococcus multilocularis in foxes (Vulpes vulpes) in Lorraine. Effects on human contamination]. Rec Med Vet Ec Alfort. 1987;163(10):839-43.

28. Otero-Abad B, Torgerson PR. A systematic review of the epidemiology of echinococcosis in domestic and wild animals. PLoS Negl Trop Dis. 2013;7(6):e2249. http://dx.doi. org/10.1371/journal.pntd.0002249 PMID:23755310

29. Immelt U, Thelen U, Eskens U. Investigation of Echinococcus multilocularis in red foxes and their possible relationship to human alveolar echinococcosis. Tierarztl Umsch. 2009;64(4):199-212.

30. Denzin N, Schliephake A, Ewert B. [Echinococcus multilocularis in red foxes in Saxony-Anhalt: identification of areas of increased risk of infestation and association of the infestation probability with the average annual maximum temperature]. Berl Munch Tierarztl Wochenschr. 2005;118(9-10):404-9. German. PMID:16206929

31. Rausch RL. Life cycle patterns and geographic distribution of Echinococcus multilocularis. In: The biology of Echinococcus and hydatid disease. Thompson RCA, editor. London: George Allen and Unwin: 1986. p. 58-80.

32. Vuitton DA, Zhou H, Bresson-Hadni S, Wang Q, Piarroux $M$, Raoul F, et al. Epidemiology of alveolar echinococcosis with particular reference to China and Europe. Parasitology. 2003;127 Suppl:S87-107.

33. Delattre P, Pascal M, Le Pesteur MH, Giraudoux P, Damange JP. Caractéristiques écologiques et épidémiologiques de l'Echinococcus multilocularis au cours d'un cycle complet des populations d'un hôte intermédiaire (Microtus arvalis). [Ecological and epidemiological characteristics of Echinococcus multilocularis in a complete cycle of the population of an intermediate host (Microtus arvalis)]. Canadian Journal of Zoology. 1988;66:2740-50. French.

34. Thompson RCA, McManus DP. Aetiology: parasites and lifecycles. In: WHO/OIE Manual on echinococcosis in humans and animals: a public healh problem of global concern. Eckert J, Gemmel MA, Meslin FX, Pawlowski ZS, editors. Paris/ Geneva: World Organisation for Animal Health/World Health Organization; 2001. p. 1-19. Available from: http://whqlibdoc. who.int/publications/2001/929044522X.pdf

35. Casulli A, Bart JM, Knapp J, La Rosa G, Dusher G, Gottstein $B$, et al. Multi-locus microsatellite analysis supports the hypothesis of an autochthonous focus of Echinococcus multilocularis in northern Italy. Int J Parasitol. 2009;39(7):83742. http://dx.doi.org/10.1016/j.ijpara.2008.12.001 PMID:19150351

36. Giraudoux P, Craig PS, Delattre P, Bao G, Bartholomot B, Harraga $S$, et al. Interactions between landscape changes and host communities can regulate Echinococcus multilocularis transmission. Parasitology. 2003;127(7) Suppl:S121-31. http:// dx.doi.org/10.1017/S0031182003003512 PMID:15027609

37. Said-Ali Z, Grenouillet F, Knapp J, Bresson-Hadni S, Vuitton DA, Raoul F, et al.; Francechino Network. Detecting nested clusters of human alveolar echinococcosis. Parasitology. 2013;140(13):1693-700. http://dx.doi.org/10.1017/ So031182013001352 PMID:23962413

38. Guislain M-H, Raoul F, Giraudoux P, Terrier M-E, Froment G, Ferté $\mathrm{H}$, et al. Ecological and biological factors involved in the transmission of Echinococcus multilocularis in the French Ardennes. J Helminthol. 2008;82(2):143-51. http://dx.doi. org/10.1017/So022149X08912384 PMID:18394209

39. Burlet P, Deplazes P, Hegglin D. Age, season and spatiotemporal factors affecting the prevalence of Echinococcus multilocularis and Taenia taeniaeformis in Arvicola terrestris. Parasit Vectors. 2011;4(1):6. http://dx.doi.org/10.1186/17563305-4-6 PMID:21247427

40. Guislain MH, Raoul F, Poulle ML, Giraudoux P. Fox faeces and vole distribution on a local range: ecological data in a parasitological perspective for Echinococcus multilocularis. Parasite. 2007;14(4):299-308. http://dx.doi.org/10.1051/ parasite/2007144299 PMID:18225418

41. Kern P. Clinical features and treatment of alveolar echinococcosis. Curr Opin Infect Dis. 2010;23(5):505-12. http:// dx.doi.org/10.1097/QCO.ob013e32833d7516 PMID:20683265

42. Combes B, Comte S, Raton V, Raoul F, Boué F, Umhang G, et al. Westward spread of Echinococcus multilocularis in foxes, France, 2005-2010. Emerg Infect Dis. 2012;18(12):2059-62. http://dx.doi.org/10.3201/eid1812.120219 PMID:23171707

43. Combes B, Comte S, Raton V, Raoul F, Umhang G, Favier S, et al. Expansion géographique du parasite Echinococcus multilocularis chez le renard en France. [Westward spread of Echinococcus multilocularis in foxes in France]. Bulletin épidémiologique, santé animale et alimentation. 2013;57:168. French. Available from: http://agriculture.gouv.fr/ Bulletin-epidemiologique-no-57 